\title{
Editorial
}

\section{Reinvention: Patterns in Uncertainty}

Auni Siukosaari, University of Warwick

I would like to extend a warm welcome to all of our readers to this new issue of Reinvention: An International Journal of Undergraduate Research, Volume 14, Issue 2 (14.2). As the world continues to recover from the Covid-19 pandemic, uncertainty persists as a theme in all of our lives, and familiar as well as new patterns are beginning to emerge.

This issue (14.2) provides an extremely rich and diverse set of undergraduate papers that push the boundaries of their respective fields. From the examination and analysis of literature that reveals to us important aspects of history and power structures, to the use of machine learning in music classification, to the examination of the phenomenology of ASMR, all the way to the study of one of the most pressing issues of our time - climate change and its impacts - this issue offers you a variety of insightful and thought-provoking research.

What these papers all have in common is their appreciation of patterns and finding connections in uncertain, under-studied or under-explored areas. While the fields of study vary greatly, their contributions all highlight useful and complex patterns that reveal valuable aspects of our lives that we might not have necessarily realised. This idea is captured in the cover of this issue, created by Shreya Sridharan, which represents a variety of patterns intersecting one another. As our world continues to get more interconnected than ever, the ability to find, appreciate and learn from complex patterns is increasingly valuable.

To begin this issue, Curtis Thompson's paper, 'Lyric-Based Classification of Music Genres Using Hand-Crafted Features' dives into the intersection of machine learning and music classification. His paper is extremely relevant in an age where we are surrounded by musicstreaming services that benefit their users by classifying music by genre and, notably, his prediction accuracies improve on those of previous studies.

Cameron Cross's 'Cloak and Cruentation: Power, (In)Visibility and the Supernatural in the Nibelungenlied", on the other hand, examines the Medieval epic poem the 'Nibelungenlied' and the narrative function of the two supernatural elements in it, the cloak and cruentation. 
Through focusing on this piece of German literature, he highlights how the dichotomy of the visible/invisible reveals deeper power structures.

Rory Bines-Morris's 'Reappearing in Different Forms: Ancient and Contemporary Irish Hunger in Bog Child focuses on Siobhan Dowd's novel Bog Child and examines the repetition of history, particularly the extended history of self-sacrifice and hunger in Ireland, as well as the gendered patterns that persist. His paper offers an insightful analysis of historical cultural trauma and offers compassionate ends to its repetition.

Samuel Inskip's 'Effects of Anthropogenic Climate Change on the Occurrence of Supercellular Tornadoes in the USA' investigates the ever-pressing relationship between climate change and natural disasters. With a focus on tornadoes in the USA, his research supports efforts for better tornado preparedness and predictions in affected areas as climate change progresses.

Finally, Anna Lindfors and Heather E. Branigan's ‘From Cathartic “Brain Tingles” to Scratching Chalkboard Sensations: An Exploratory Study Investigating the Phenomenological Aspects of ASMR' explores the relatively under-studied field of ASMR. The authors present a model for future research that accounts for the complexity and variability of individual experiences across different dimensions (Physical, Psychological and Social), which offers alternative ways of capturing the diverse experiences and connections people have to ASMR.

Patterns, both old and new, are everywhere to be found, and this issue hopes to shed light on a few incredibly important ones. The quality of the papers in this issue has been extraordinary, and I want to thank and congratulate all the authors who contributed. I hope these papers, their findings and themes, resonate with our readers and provide a greater understanding and appreciation of undergraduate research across the globe. As always, we look forward to new submissions and collaborative projects for our next issue as we continue to work with undergraduate students to uplift their valuable contributions to academic literature.

My time as Editor at Reinvention is coming to an end, and I am honoured to be introducing Shreya Sridharan as the next Editor following this publication. My experience at Reinvention has been incredibly rewarding and has continued to deepen my appreciation for the promotion of international and interdisciplinary voices in academic spaces. I want to thank the Journal Managers at Warwick for their continued support, all the incredible authors I have worked with and learnt from along the way, and the stellar editorial team I was privileged to be a part 
of. I have no doubt Shreya and the team are going to do an incredible job with the journal going forwards.

To cite this paper please use the following details: Siukosaari, A. (2021), 'Editorial', Reinvention: an International Journal of Undergraduate Research, Volume 14, Issue 2, https://reinventionjournal.org/article/view/923. Date accessed [insert date]. If you cite this article or use it in any teaching or other related activities please let us know by e-mailing us at Reinventionjournal@warwick.ac.uk. 